justified in concluding that their evidence refuted the hypothesis that exposure to influenza in the second trimester of pregnancy was associated with an increased risk of schizophrenia. Their numbers were too small and their arithmetic faulty.

ADAMS, W \& Kendell, R. E. (1996) Influenza and schizophrenia (letter). British Journal of Psychiatry, 169, 252-253.

Cannon, M., Cotter, D., Coffey, V. P., et al (1996) Prenatal exposure to the 1957 influenza epidemic and adult schizophrenia: A follow-up study. British Journal of Psychiatry, 168 368-371.

Crow, T. J. \& Done, D. J. (1992) Prenatal exposure to influenza does not cause schizophrenia. British Journal of Psychiatry, 161, 390-393.

W. ADAMS

University of Edinburgh Medical School R. E. KENDELL

Edinburgh EH8 9 AF

\section{The uses and limitations of mental health service needs indices}

SIR: While it is now taken as axiomatic that local mental health services should be planned in relation to needs, the definition of need, the distinction between population and individual levels of need, and the ways in which need can be operationalised all remain to be clarified. The paper by Smith $e t$ al (1996) adds further quantitative evidence to support the population-level estimates of need, which have been described elsewhere (Thornicroft et al, 1992). The paper concludes that the index of needs produced by Smith $e t$ al shows that the expected rates of local service use may vary by a factor of more than three times between Huntingdon and Central Manchester, the least and most morbid areas included in the study. At first sight this is a remarkable finding given that actual National Health Service expenditure on mental health services varies by a factor of about 1.5 in practice. Nevertheless, the findings of Smith et al may still be an underestimate. The recent household National Psychiatric Morbidity Survey, conducted by the Office of Population Censuses and Surveys (1995), revealed a range of annual period prevalence for psychotic disorders between 0.2 and $0.9 \%$ of the total population, that is a 4.5 -fold variation. Similarly, the MINI computerised program by Glover (1996) also finds approximately four-fold variations in actual utilisation of psychiatric in-patient beds. There does seem to be steadily accumulating evidence that the most and least socially deprived parts of Britain will have, approximately, morbidity levels double and half the national average, respectively; that is a four-fold variation.
Despite the value of the paper by Smith et al, and the parallel work in producing the MINI index, these calculations are still, at this stage, of somewhat academic interest. Such formulae guide the allocation of monies from the NHS Executive to purchasing authorities. Purchasing authorities have very wide degrees of discretion about how their total budget may be spent for their varying categories of health care. There is no overall discernible pattern of actual expenditure at the provider level, which varies in relation to any assessment of population need. If there is an overall national pattern, it reflects somewhat higher expenditure in districts which did have long-stay institutions and which appear to have retained some budgetary advantage. Two issues arise: first, in the funding distribution formula adopted by the Department of Health, which is a variation on the proposals put forward by the York Group two years ago, there remains a $20 \%$ component of the total budget which is not currently weighted. It is therefore open to discretion of the NHS Executive to re-weight this in line with emerging evidence of variations in mental health care needs that are greater than previously expected. Second, it is becoming clearer that it will be necessary for the NHS Executive to provide clearer guidance to purchasers on the expected proportion of their total budget which should be spent for mental health services in each local area.

Glover, G. (1996) The Mental Illness Needs Index (MINI). In Commissioning Mental Health Services (eds G. Thornicroft \& G. Strathdee). London: Her Majesty's Stationery Office.

OfFice of Population Censuses and Surveys. (1995) The National Psychiatric Morbidity Survey: Household Survey. London: Her Majesty's Stationery Office.

Smith, P., Sheldon, T. A. \& Martin, S. (1996) An index of need for psychiatric services based on in-patient utilisation. British Journal of Psychiatry, 169, 308-316.

ThORNICROFT, G., BREWIN, C. \& Wing, J. (1992) Measuring Mental Health Needs. London: Royal College of Psychiatrists.

Institute of Psychiatry

G. THORNICROFT

De Crespigny Park

London SE5 8 AZ

\section{Treatment of severe personality disorders}

SIR: As a member of a community mental health team, that in our case includes the local in-patient unit, I found the paper by Norton \& Hinshelwood (1996) on the treatment of severe personality disorders troubling in many respects. It reads like a sales pitch for a particular type of facility, particularly given the obvious commitment of the authors 